\title{
Forward Osmosis: Potential use in Desalination and Water Reuse
}

\author{
Ali Altaee*
}

\author{
School of Engineering University of the West of Scotland Paisley PA1 2BE, the UK
}

\begin{abstract}
There has been a recurring interest in using Forward Osmosis (FO) process in water treatment and desalination. Despite the promising results from pilot and bench scale experiments the technology is still not commercialized yet. This is due to the complicated nature of the process which usually involves multiple stages of treatment in addition to the FO membrane process. Unfortunately, most of the recent studies were focused on studying the FO process alone and didn't provide enough data about the actual cost of the process as whole which includes the osmotic agent regeneration stage/s. This issue resulted in some uncertainties about the total cost of the water treatment by the process. Furthermore, more data are required to evaluate the impact of the osmotic agent losses on the overall cost and efficiency. In case if the draw solution is regenerated by membrane treatment, a suitable membrane should be selected to ensure an optimal salt rejection. For power generation by Pressure Retarded Osmosis (PRO) process, there was an evident progress. However, the process is site specific; i.e. it is dependent of the availability of the draw and donor solution. This suggested that the process is applicable to certain areas but can't be generalized.
\end{abstract}

Keywords: Please provide keywords.

\section{INTRODUCTION}

Due to the increasing demands on fresh water supply and contamination of ground waters, desalination becomes the choice option for water supply in water shortage areas. Thermal and membrane technologies are the forefront processes for seawater desalination. Multi Stage Flashing (MSF) and Multi Effect Distillation (MED) are the leading processes in thermal technologies while Reverse Osmosis (RO) dominates the membrane desalination technologies [1-3]. The thermal processes are widely used in the Gulf region of the Middle East due the difficult nature of gulf water such as high salinity and concentrations of impurities. In the last decade, this trend has been changed in favor of the RO process due to the development of high performance RO membranes for seawater desalination. Worldwide, RO process is the most common technology for seawater desalination [3, 4]. Mainly, this is because of its reliability and lower power consumption compared to the thermal technologies [4, 5]. The cost of water desalination by the RO process is less than USD 1 $\$ / \mathrm{m}^{3}[6,7]$. Unfortunately, the cost of RO desalination is still unaffordable to many countries.

As a result, scientists and researchers are investigating cheaper processes for seawater desalination such as FO [6-8]. The attractiveness of the FO process consists in its low power consumption, easy to scale up, and potential high recovery rate $[6,8$, 9]. The operating cost of FO process is much lower

${ }^{*}$ Address correspondence to this author at the School of Engineering University of the West of Scotland Paisley PA1 2BE, the UK, Tel +971507356657;

Email: alialtaee@hotmail.com than $\mathrm{RO}$ and thermal processes. In principle, FO relies on the for water transport across semi permeable membrane. Freshwater transports across the semipermeable membrane from the low to the high concentration solution due to the osmotic pressure gradient. A number of chemical compounds have been used as a draw solution in FO process such as table salt, magnesium sulfate, glucose, ammonia carbon dioxide, and magnesium chloride [9, 10]. In practice, draw solution is recycled and reused to reduce the cost of desalination. This is typically achieved either by thermal or membrane filtration processes.

Previous studies have shown there is a number of physical and chemical factors which affect the efficiency and cost of the FO process. Amongst these factors are; salt diffusion from the seawater to the draw solution, osmotic agent diffusion across the membrane, and concentration polarization. Because of the adverse impact of these factors, the actual performance of FO is significantly lower than the theoretical performance [11]. Yet, there isn't enough information about the overall effect of salt diffusion on the product water quality and the desalination cost. Although osmotic agent can be regenerated and reused, none of the aforementioned regeneration processes are capable of completely recycling the osmotic agent without losses. Depending on the regeneration process used for osmotic agent recycling, salt diffusion will affect the quality and cost of the product water. For example, the membrane processes is affected by the type of the osmotic agent and membrane used in the regeneration process. Different types of membranes were used such as RO, Nanofiltration (NF), and membrane distillation (MD). 
In addition to seawater desalination, FO was proposed for power generation; the technique is known as Pressure Retarded Osmosis (PRO) [9, 10, 12]. It was first suggested by Loeb [13] and there is a wealth of literature about describing its potential and application in power generation. The mechanism of PRO operation is similar to that explained above but after leaving the FO membrane, preferably pressurized, the draw solution is fed to a turbine system to convert the hydraulic energy to an electrical power. The application of PRO in power generation was limited by the membranes characteristics and efficiency until the breakthrough made by StatKraft which built the world first pilot plant for power generation in Norway [14]. The pilot plant used freshwater as donor solution and seawater as a draw solution. The optimal performance of PRO can be achieved when fresh water is used as a donor solution; this will eliminate the problem of internal concentrative concentration polarization. StatKraft plant is the largest in the world which demonstrated the feasible scalability of PRO from bench to pilot scale. To date, there is no data about the economical feasibility of the PRO in power generation. It should be stressed here that the type and concentration of the osmotic agent have a significant impact on the performance of FO process. This paper pinpointed the major drawbacks in FO applications and commercialization. The paper also submitted a critical review from engineering perspective with regard to $F O$ process optimization.

\section{FO FOR SEAWATER DESALINATION}

Desalination is an essential process for fresh water supply in water stressed area. The cost of desalination is still high and need to be reduced especially for high salinity feed waters. FO, therefore, received a lot of attention in the past decade of being a competitive process for seawater desalination compared to the conventional processes. There are a number of technical and operating factors which affect the efficiency of the process. Technical factors such as internal and external concentration polarizations were found to have detrimental impact on the membrane flux and the recovery rate. The phenomenon of concentration polarization is associated with the membrane characteristics and it is mainly due to the salt concentration at the membrane surface relative to bulk solution $[9,11]$. Depending on the flow mode of the draw and feed solutions, concentration polarization is classified into internal and external effects [11]. The internal effect occurs at the lumen or at the support layer side of the membrane while the external occurs on the membrane active layer $[11,15]$. Concentrative concentration polarization usually refers to the change in the concentration of feed solution and it is due to the increase in the concentration of feed solution at the membrane surface leading to a decrease in the osmotic pressure gradients across the membrane [11, 15]. As a result, fresh water flow across the membrane declines with time. On contrast, the dilutive concentration polarization is associated with the draw solution which results in a reduction in the concentration of draw solution. In response to this effect the osmotic pressure gradient is decreased as well as water flux across the membrane. The recent advance in the membrane manufacturing technology successfully minimized the internal concentration polarization problem. This was achieved by reducing the thickness of the membrane support layer [16]. However, the effect of external concentration polarization is an inherent nature of the FO membrane process and can't be avoided.

The effect of internal concentration polarization was found to be more serious than the external concentration polarization (Figure 1) [7]. This finding is especially important when the FO membrane is operated in the RO mode or the draw solution in the lumen side of the membrane. Pilot and bench scale experiments showed a sharp drop in the membrane flux under the effect of internal concentration polarization. Although the new FO membranes have successfully reduced the effect of internal dilutive and concentrative concentration polarization, it can't be completely eliminated. Therefore, the efficiency of FO process will still be affected by the internal concentration polarization phenomenon. The new experimental work showed that FO process operates better in inside to outside flow mode or when the draw solution is in the shell side and the feed solution in the lumen side. Basically, this is due to the higher membrane flux in the latter operation mode. But, it should be noted here this fact holds true when the FO process is applied for seawater desalination in the conventional way. In some cases, as will be discussed later, it is preferred to have the draw solution in the lumen not to improve the membrane flux but to reduce the membrane fouling propensity [15]. This is especially true if the donor solution has a high concentration of fouling agents such as wastewater effluent.

It is highly desirable to achieve a high recovery rate in the desalination process. At the present, the recovery rate in $\mathrm{RO}$ seawater desalination is less than $50 \%$ while it is about $30 \%$ in the thermal desalination 


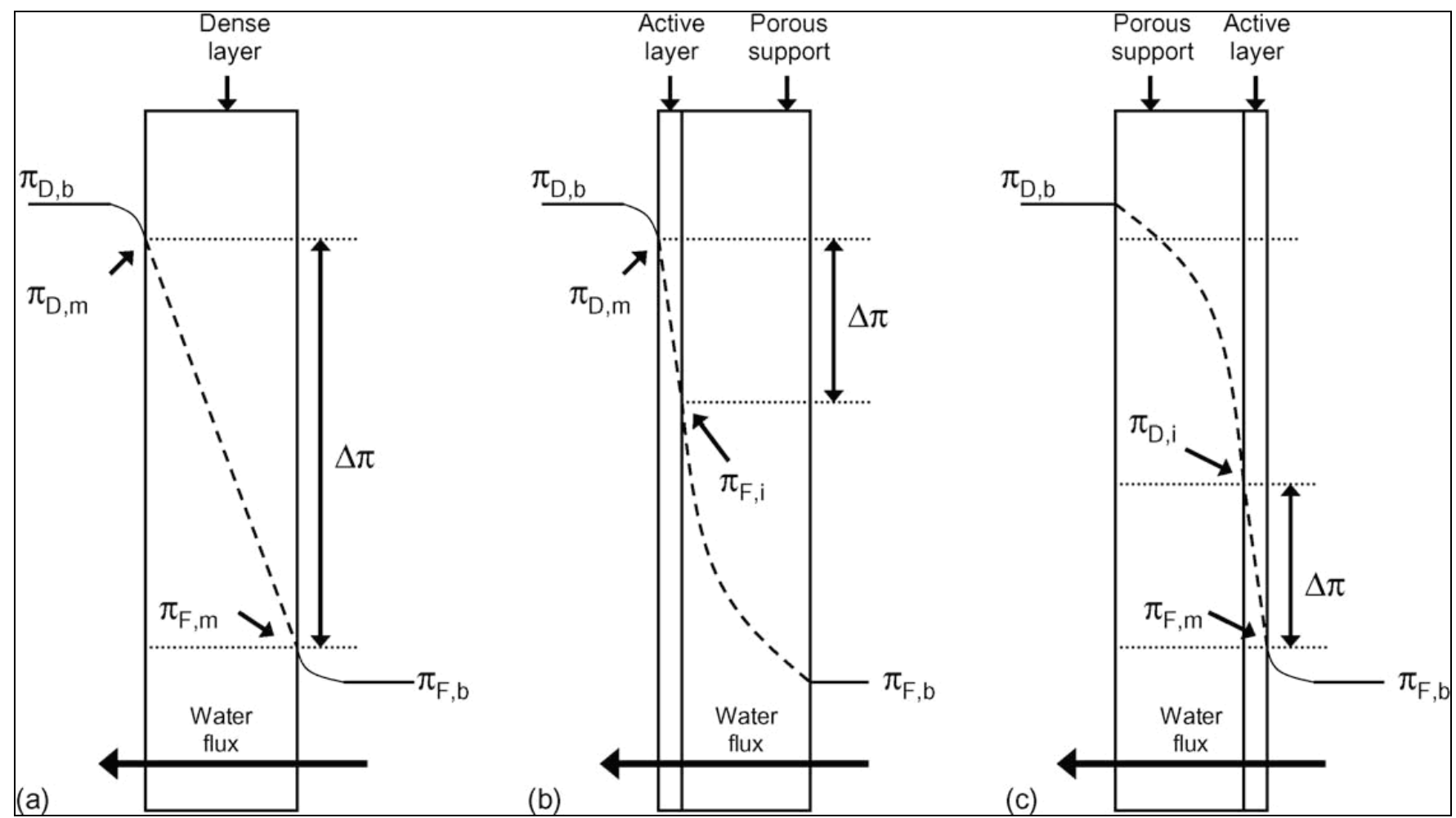

Figure 1: Concentration polarization in FO membrane (a) A symmetric membrane (b) An asymmetric membrane draw solution facing the active layer (c) An asymmetric membrane feed solution facing the active layer (Jeffery et al., 2006).

processes (MSF and MED) [4, 8, 17, 18]. Osmotic pressure gradient is the main mechanism by which fresh water transports across the membrane in the FO process. For a given feed water/seawater TDS, the recovery rate can be increased by increasing the concentration of draw solution. However, the experimental work demonstrated that the relationship between the concentration of draw solution and the recovery rate is not linear (Figure 2). Water flow across the membrane dilutes the draw solution at the membrane surface forming a micro boundary layer adjacent to the membrane surface. The concentration at the boundary layer is lower than that in the bulk solution which results in reducing the driving force of water transport from the feed to the draw solution. As shown in Figure 2, the increase in the osmotic pressure gradient resulted in a proportional increase in the recovery rate. Although the relationship was linear at low osmotic pressure gradient, it is changed at high osmotic pressure gradients. Primarily, this is due to the concentration polarization effect at the membranesolution interface. It should be noted here that the energy requirement for regeneration and fresh water extraction is increased with increasing the concentration of draw solution. This is because of the higher concentration of the diluted draw solution has to be regenerated (Figure 2). Accordingly, a subsequent increase in the concentration of draw solution wouldn't necessarily lead to the desirable improvement in the performance of $\mathrm{FO}$ process.

The regeneration process of draw solution is the most expensive stage in the FO desalination process. Conversely to the FO process, which is driven by the natural osmosis phenomenon, the regeneration process is relatively more power intensive. Typical osmotic pressure of the diluted draw solution is equal or higher than the osmotic pressure of the feed solution. Both membrane and thermal processes were proposed for freshwater extraction and draw solution regeneration $[9,10]$. NF, $R O$, and $M D$ membranes were proposed for the regeneration of draw solution and fresh water extraction [9, 12]. Each type of membranes has its own advantages and disadvantages which need to be considered upon choosing a suitable membrane for the regeneration process. Thermal processes, otherwise, are used for the regeneration of draw solution [20].

\subsection{Membrane Processes for Draw Solution Regeneration}

The experimental work demonstrated the applicability of membrane processes such as NF, RO and $\mathrm{MD}$ for the draw solution regeneration and 


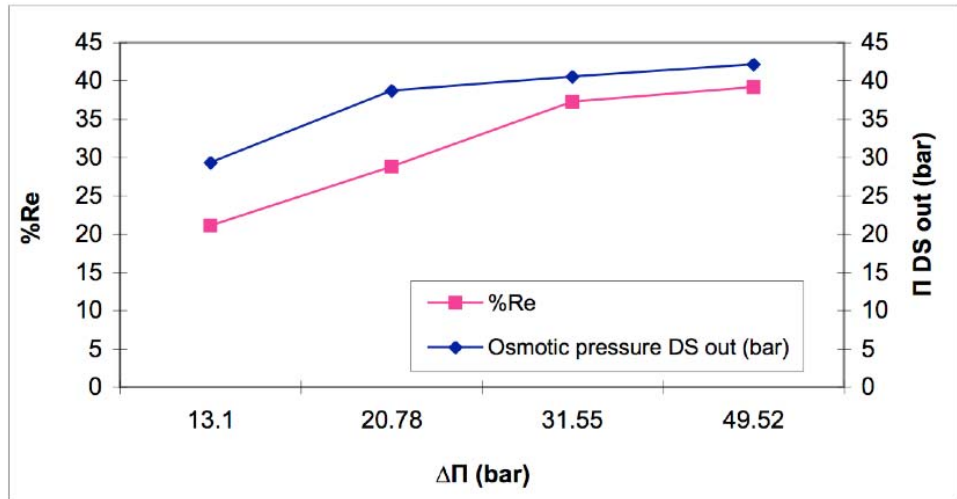

Testing condition: feed temperature $25^{\circ} \mathrm{C}, \mathrm{pH} 7.6$, recovery rates are $21 \%, 29 \%, 37 \%$ and $39 \%$, Cf 34760

Figure 2: Effect of osmotic pressure on recovery rate and the concentration of diluted draw solution.

concentration. The application of membrane process is affected by:

1. Type of the osmotic agent used in the draw solution

2. The concentration of draw solution

3. The concentration of the feed water

4. Type of the membrane

For instance, the permeability of NF membranes is higher than RO membranes but they exhibit a lower rejection rate compared to the RO membranes. NF membranes, therefore, are more suitable in the regeneration of low concentration and multivalent osmotic agent. Commercial NF membranes are manufactured to tolerate a maximum feed pressure not exceeding a forty bar. Practically, this pressure is out of the range required for the treatment a diluted draw solution for seawater desalination i.e. feed water osmotic pressure is around 27 bar. Otherwise the recovery rate of NF membrane, if used in seawater desalination, will not be economical. Therefore, NF membranes are suitable for the regeneration of a draw solution having an osmotic pressure less than seawater such as brackish water. For simplicity, it is assumed here that the osmotic pressure of the brackish water to be treated by FO process is 1.6 bar (feed TDS 2000 ppm $\mathrm{NaCl}$ ) and the recovery rate is $75 \%$. Ideally, in $\mathrm{FO}$ process the osmotic pressure of the diluted draw solution will be at least equal to that of the feed solution concentrate; i.e. 6.5 bar (based on $75 \%$ recovery rate). ROSA software by Filmtec was used in this paper to estimate the membrane feed pressure for the regeneration process. Two different draw solutions were tested here $\left(\mathrm{NaCl}\right.$ and $\left.\mathrm{MgSO}_{4}\right)$ to investigate the effect of draw solution on the membrane performance and product water quality. The cost of the regeneration process and product water quality is also affected by the type of membrane used in the regeneration process. For comparison purpose, NF and BWRO membranes were applied for the draw solution regeneration and concentration. The simulation results showed that the permeate TDS was lower when BWRO membrane was used for draw solution regeneration (Figure 3). The permeate TDS was also affected by the type of draw solution (Figure 3). For a given BWRO membrane, a lower permeate concentration was achieved when $\mathrm{NaCl}$ was used as a draw solution. This is because of the lower concentration of $\mathrm{NaCl}$ was required for the generation of same osmotic pressure compared to $\mathrm{MgSO}_{4}$. The required concentration of $\mathrm{NaCl}$ and $\mathrm{MgSO}_{4}$ in the draw solution to generate an osmotic pressure equivalent to 6.5 is $8250 \mathrm{ppm}$ and $29972 \mathrm{ppm}$ respectively. As such, $\mathrm{NaCl}$ is likely to be more efficient osmotic agent than $\mathrm{MgSO}_{4}$ if BWRO membrane is used for the draw solution regeneration. It is clearly shown in Figure 3 that there was a proportional increase in the permeate TDS with increasing the recovery rate $[8,19]$. On the other hand NF membranes are not suitable for the regeneration of monovalent osmotic agent due to the low rejection rate to monovalent ions (Figure 3 ). Eventhough BWRO membrane showed a higher rejection rate to mono and multivalent ions osmotic agent but this was at the cost of higher energy consumption (Figure 4). As expected, the specific energy consumption was higher in case of BWRO membrane especially when the draw solution was made of $\mathrm{MgSO}_{4}$. This is because: 


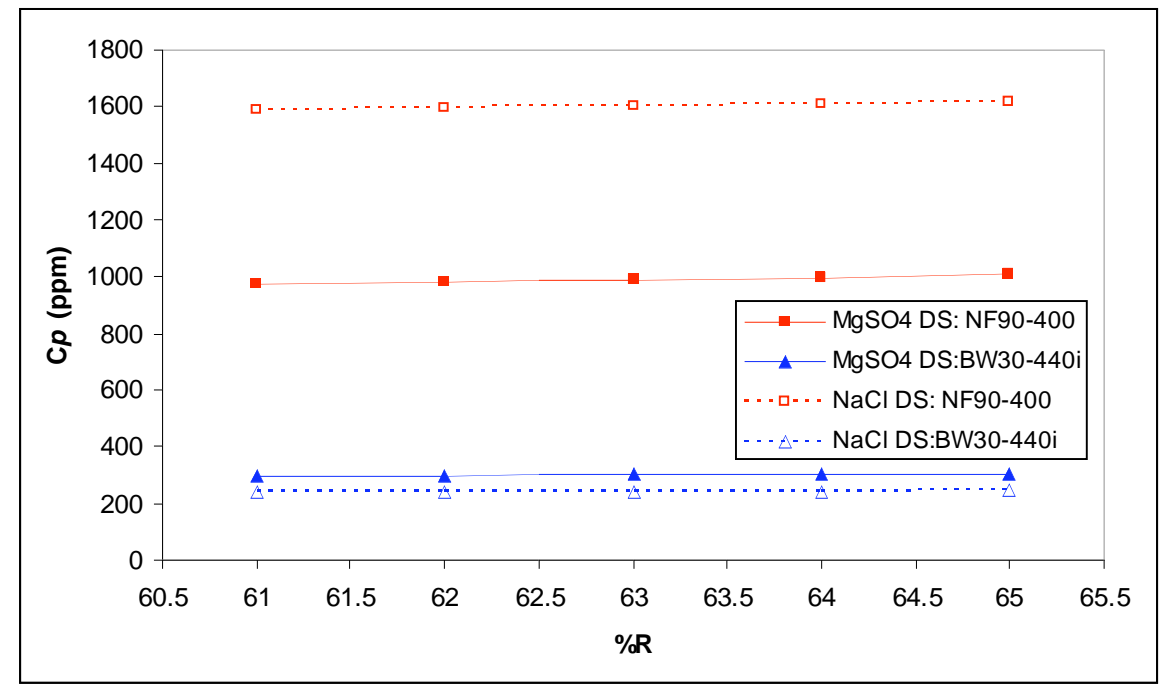

Testing condition: feed temperature $25^{\circ} \mathrm{C}, \mathrm{pH} 7.6$, recovery rates are $61 \%-65 \%, \mathrm{Cf} 34760, \mathrm{Q}_{\mathrm{f}} 7 \mathrm{~m}^{3} / \mathrm{h}, \mathrm{Cf}_{\mathrm{MgSO} 4} 29971 \mathrm{ppm}, \mathrm{Cf}_{\mathrm{NaCl}} 8250 \mathrm{ppm}$

Figure 3: Effect of recovery rate on the permeate concentration.

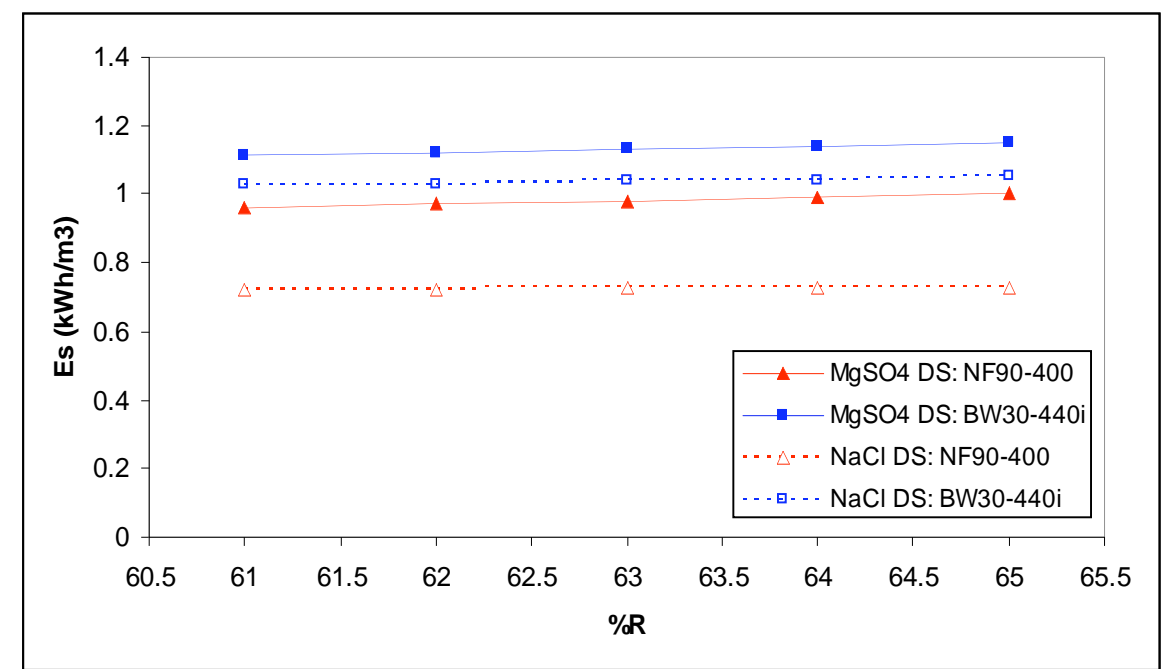

Testing condition: feed temperature $25^{\circ} \mathrm{C}, \mathrm{pH} 7.6$, recovery rates are $61 \%-65 \%$, Cf $34760, \mathrm{Q}_{\mathrm{f}} 7 \mathrm{~m}^{3} / \mathrm{h}, \mathrm{Cf}_{\mathrm{MgSO} 4} 29971 \mathrm{ppm}, \mathrm{Cf}_{\mathrm{NaCl}} 8250 \mathrm{ppm}$

Figure 4: Power consumption as a function of recovery rate.

1. $\mathrm{MgSO}_{4}$ has more affinity to the membrane surface because of the higher ionic charge compared to $\mathrm{NaCl}$

2. The higher concentration of $\mathrm{MgSO}_{4}$ required for the generation of osmotic pressure equivalent to that of $\mathrm{NaCl}$ Salt. Higher concentration causes higher concentration polarization.

3. Higher membrane rejection to $\mathrm{MgSO}_{4}$

$C_{w}=C_{b} * C P[1]$
Where $C_{w}$ is the concentration at the membrane wall, $C_{b}$ is the bulk concentration and $C P$ is the concentration polarization factor.

Regardless the type of osmotic agent, the specific energy consumption decreased when NF was used instead of BWRO membrane for the draw solution regeneration. The specific energy consumption increased with the recovery rate increase which is typically observed in the membrane filtration processes.

BWRO membranes have a tighter structure than NF membranes which render them an expensive option for 
treating the draw solution because of the high feed pressure requirement (Figure 5). The simulation results showed that the feed pressure was higher when BWRO membrane was used. In case of NF membrane the power consumption decreased when $\mathrm{NaCl}$ was used as a draw solution because of the lower NF rejection rate to monovalent ions. As such $\mathrm{NaCl}$ is not recommended as an osmotic agent if NF membranes are used for the regeneration of the draw solution. The BWRO membrane required a higher feed pressure for the filtration of $\mathrm{MgSO} 4$ than $\mathrm{NaCl}$ (Figure 5). This was probably attributed to the high rejection rate of $\mathrm{MgSO}_{4}$ by BWRO membrane and hence the concentrate pressure was higher than that for $\mathrm{NaCl}$ (Figure 6). Indeed, the concentrate osmotic pressure increased with increasing the recovery rate in both draw solutions; i.e. $\mathrm{NaCl}$ and $\mathrm{MgSO}_{4}$. Therefore, it is preferable to use $\mathrm{NaCl}$ or any monovalent ions of high osmotic pressure in $\mathrm{FO}$ process if tight membranes such as BWRO/RO are used in the regeneration process.

For seawater desalination, RO membranes should be used in conjunction with FO membranes. High pressure seawater RO membranes are preferable for water extraction and draw solution concentration. ROSA was used to demonstrate the applicability of RO membranes for the draw solution concentration and regeneration. Three different types of osmotic agents were investigated; $\mathrm{MgSO}_{4}, \mathrm{MgCl}_{2}$ and $\mathrm{NaCl}$ and a number of recovery rates ranged between 42 and 54 at $3 \%$ intervals were examined. The results showed that

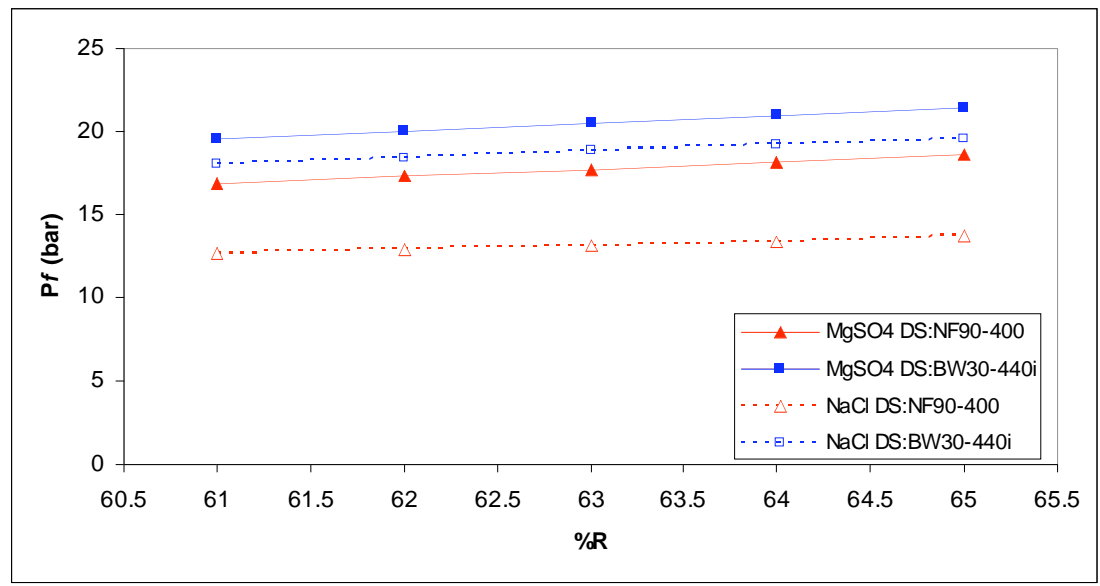

Testing condition: feed temperature $25^{\circ} \mathrm{C}, \mathrm{pH} 7.6$, recovery rates are $61 \%-65 \%$, Cf $34760, \mathrm{Q}_{\mathrm{f}} 7 \mathrm{~m}^{3} / \mathrm{h}, \mathrm{Cf}_{\mathrm{MgSO}} 29971 \mathrm{ppm}, \mathrm{Cf}_{\mathrm{NaCl}} 8250 \mathrm{ppm}$

Figure 5: Effect of the recovery rate on the feed pressure for NF and RO membranes.

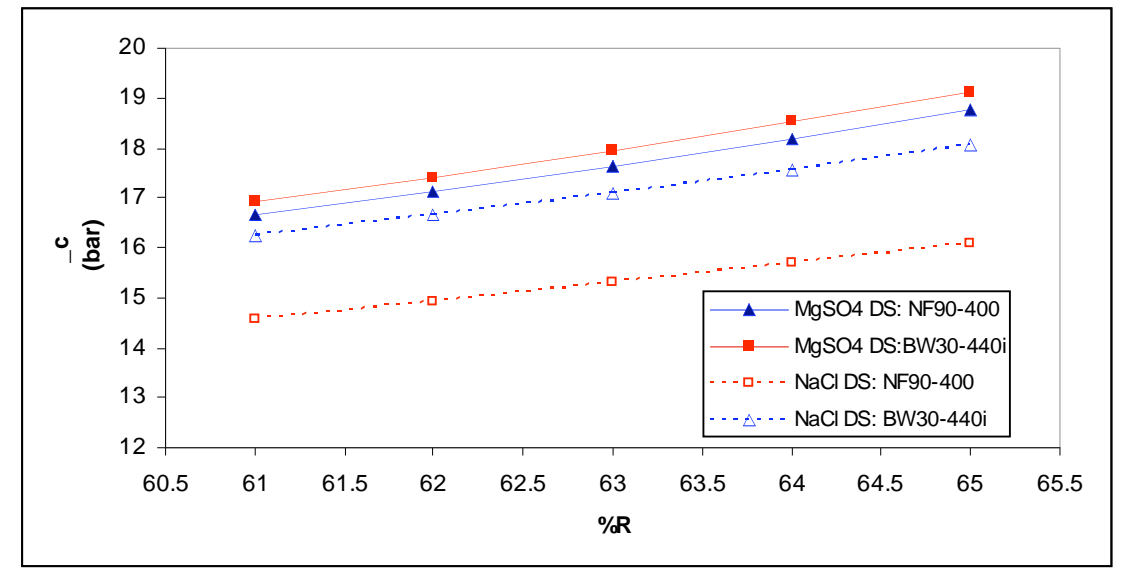

Testing condition: feed temperature $25^{\circ} \mathrm{C}, \mathrm{pH} 7.6$, recovery rates are $61 \%-65 \%$, Cf $34760, \mathrm{Q}_{\mathrm{f}} 7 \mathrm{~m}^{3} / \mathrm{h}, \mathrm{Cf}_{\mathrm{MgSO} 4} 29971 \mathrm{ppm}, \mathrm{Cf} \mathrm{NaCl}_{\mathrm{Nal}} 8250 \mathrm{ppm}$

Figure 6: Concentrate osmotic pressure at different recovery rates. 


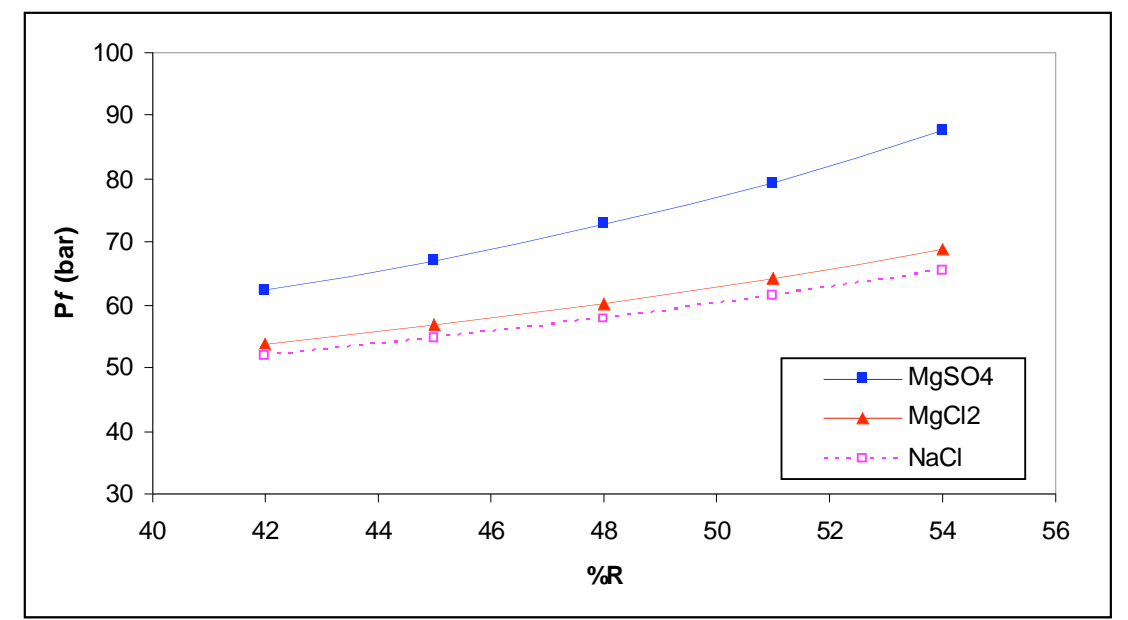

Testing condition: feed temperature $25^{\circ} \mathrm{C}, \mathrm{pH} 7.6$, recovery rates $42 \%-54 \%, \mathrm{Q}_{\mathrm{f}} 5 \mathrm{~m}^{3} / \mathrm{h}, \mathrm{Cf}_{\mathrm{MgSO} 4} 120386 \mathrm{ppm}, \mathrm{Cf}_{\mathrm{NaCl}} 36600 \mathrm{ppm}, \mathrm{Cf}_{\mathrm{mgCl}} 36600 \mathrm{ppm}$

Figure 7: Effect of recovery rate on the feed pressure.

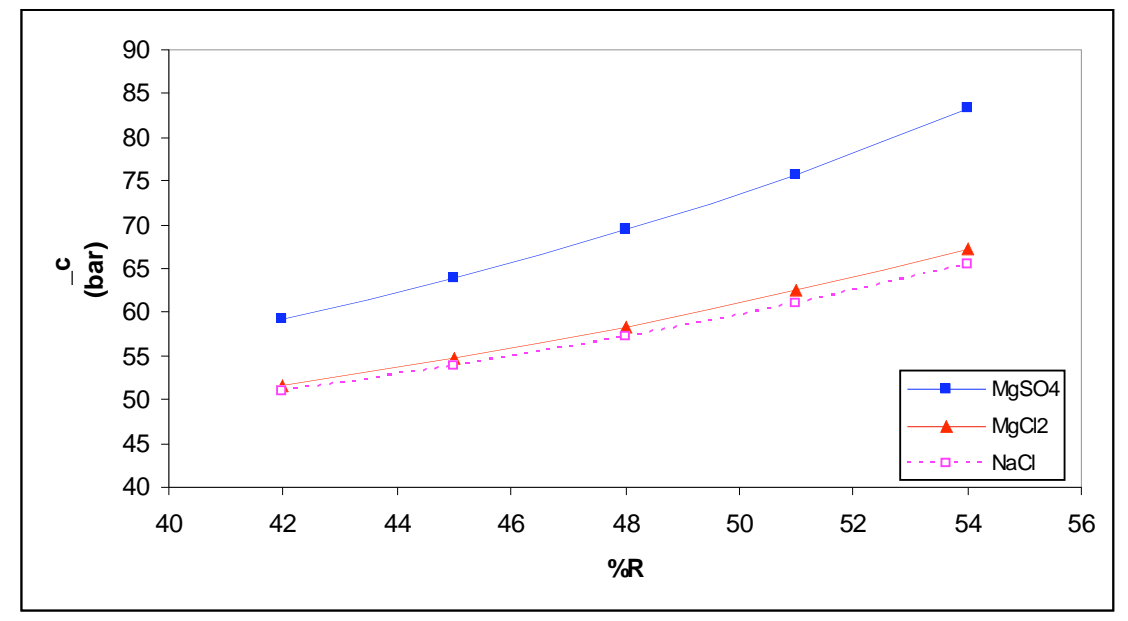

Testing condition: feed temperature $25^{\circ} \mathrm{C}, \mathrm{pH} 7.6$, recovery rates $42 \%-54 \%, \mathrm{Q}_{\mathrm{f}} 5 \mathrm{~m} 3 / \mathrm{h}, \mathrm{Cf}_{\mathrm{MgSO}} 120386 \mathrm{ppm}, \mathrm{Cf}_{\mathrm{NaCl}} 36600 \mathrm{ppm}, \mathrm{Cf}_{\mathrm{mgCl}} 36600 \mathrm{ppm}$

Figure 8: Effect of recovery rate on the concentrate concentration.

the feed pressure requirements were the highest in case of $\mathrm{MgSO}_{4}$ followed by $\mathrm{MgCl}_{2}$ and $\mathrm{NaCl}$ respectively (Figure 7). As mentioned earlier here, the reason for that was due to the high rejection rate and concentration of chemicals used to generate a desirable osmotic pressure for $\mathrm{FO}$ seawater desalination when $\mathrm{MgSO}_{4}$ was used as a draw solution. Figure 8 shows that the concentrate osmotic pressure was the highest in case of $\mathrm{MgSO}_{4}$ because of the high membrane rejection to divalent ions and complemented by the high concentration polarization problem. This substantiated the fact why $\mathrm{MgSO}_{4}$ draw solution required a higher feed pressure than $\mathrm{MgCl}_{2}$ and $\mathrm{NaCl}$. As a result, the specific power consumption was the highest when $\mathrm{MgSO}_{4}$ was used as a draw solution (Figure 9). Furthermore, the diffusion of $\mathrm{SO}_{4}$ ions is lower than $\mathrm{Cl}$ which may aggravate the intensity of concentration polarization of $\mathrm{MgSO}_{4}$ draw solution $[29,30]$.

It is evident from Figure 9 that the specific power consumption was affected by the recovery rate and it depends on the type of the osmotic agent in use. In case of MgSO4 draw solution, the simulation results show the optimal specific power consumption could be achieved at around $42 \%$ recovery rate. Then the power consumption increased with the recovery rates increase above $42 \%$ (Figure 9). Therefore, the optimal recovery rate for $\mathrm{MgSO}_{4}$ in the regeneration stage 
should be around $42 \%$. When MgSO4 was replaced by $\mathrm{MgCl}_{2}$, the optimal power consumption was achieved at a recovery rate about $48 \%$ (Figure 9 ). Accordingly, a higher recovery rate can be achieved if $\mathrm{MgCl}_{2}$ was used instead of $\mathrm{MgSO}_{4}$ as a draw solution. Finally, when $\mathrm{NaCl}$ was used as a draw solution the optimal power consumption was achieved at a recovery rate around $51 \%$ (Figure 9). Based on these results, a higher recovery rate can be achieved when $\mathrm{NaCl}$ was used in the draw solution. This is probably one of the advantages of using low molecular weight osmotic agent in the draw solution.

The advantage of using $\mathrm{MgSO}_{4}$ was the lower permeate TDS compared to $\mathrm{MgCl}_{2}$ and $\mathrm{NaCl}$ draw solutions (Figure 10). Primarily, this was due to the large molecular size and higher ionic charge of $\mathrm{MgSO}_{4}$ which was highly rejected by the RO membrane. The high permeate concentration may require an additional membrane filtration to reduce the concentration to a desirable level which leads to a higher treatment cost. The lowest permeate concentration was observed when $\mathrm{MgSO}_{4}$ was used as a draw solution. Noting that the difference between the permeate TDS in case of $\mathrm{MgSO}_{4}$ and $\mathrm{MgCl}_{2}$ was insignificant. The permeate TDS, however, decreased with increasing the recovery rate (Figure 10). This was due to increasing the permeate dilution factor with the recovery rate increase.

Although membrane hyperfiltration processes were suggested, so far, for the draw solution separation and regeneration, MD process was also investigated for the

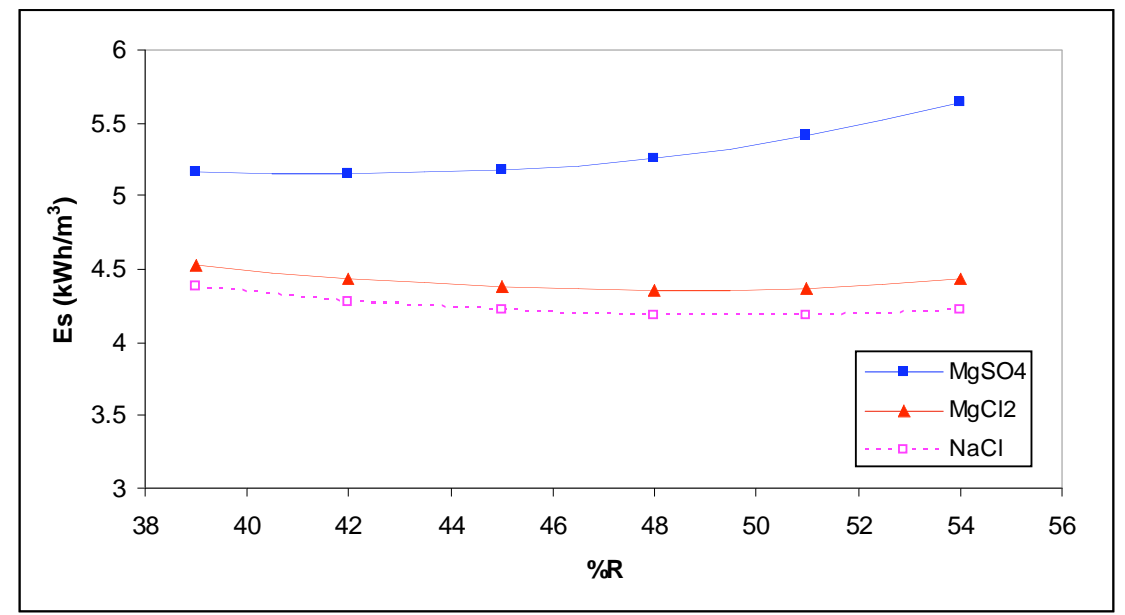

Testing condition: feed temperature $25^{\circ} \mathrm{C}, \mathrm{pH} 7.6$, recovery rates $42 \%-54 \%, \mathrm{Q}_{\mathrm{f}} 5 \mathrm{~m} / \mathrm{h}, \mathrm{Cf}_{\mathrm{MgSO} 4} 120386 \mathrm{ppm}, \mathrm{Cf}_{\mathrm{NaCl}} 36600 \mathrm{ppm}, \mathrm{Cf}_{\mathrm{mgCl}} 36600 \mathrm{ppm}$

Figure 9: Effect of recovery rate on the Specific power consumption.

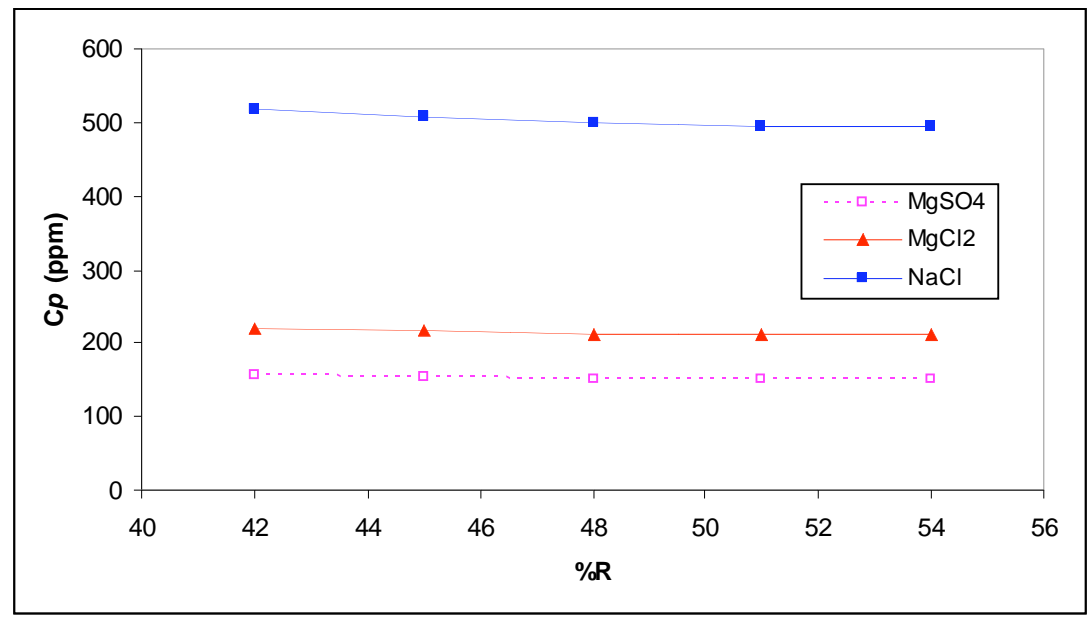

Testing condition: feed temperature $25^{\circ} \mathrm{C}, \mathrm{pH} 7.6$, recovery rates $42 \%-54 \%, \mathrm{Q}_{\mathrm{f}} 5 \mathrm{~m} / \mathrm{h}, \mathrm{Cf}_{\mathrm{MgSO} 4} 120386 \mathrm{ppm}, \mathrm{Cf}_{\mathrm{NaCl}} 36600 \mathrm{ppm}, \mathrm{Cf}_{\mathrm{mgCl}} 36600 \mathrm{ppm}$

Figure 10: permeate concentration at different recovery rates. 
regeneration of draw solution [20]. MD process was demonstrated to be feasible in the regeneration of some draw solution such as ammonia carbon dioxide $[7,9]$. In the latter process, the diluted draw solution was heated up to $60{ }^{\circ} \mathrm{C}$ before it was fed into the MD unit. Inside the membrane, ammonia carbon dioxide evaporated and condensed in the permeate side of the membrane leaving behind a fresh water in the concentrate side of the membrane. The concentration of ammonia carbon dioxide in the draw solution varies depending on the feed water solution. For instance, the FO membrane flux for seawater desalination using a draw solution contains $12 \%$ ammonia carbon dioxide was $10 \mathrm{~L} / \mathrm{h}$ [7]. After leaving the MD unit, the concentrated ammonia carbon dioxide is mixed with distilled water to prepare a draw solution of desirable concentration. Despite the low cost of draw solution regeneration by $M D$, the process suffers from several draw backs [21]:

1. Membrane wetting which results in a reduction in the permeate flux and increasing the permeate TDS.

\section{Low recovery rate}

3. Small membrane area of the MD unit

In addition, the residues of osmotic agent in the concentrate side of the MD membrane (the product water) will affect the product water quality. According to the $\mathrm{WHO}$, the concentration of ammonia in the drinking water should be less than $1 \mathrm{ppm}$. Upon chlorine reaction with ammonia to produce chloramine, the concentration of chloramine shouldn't exceed $1 \mathrm{ppm}$ as recommended by the environmental and health agencies. A high concentration of disinfectant in the drinking water triggers the formation of disinfection byproducts such as Trihalomethane (THM) which is a carcinogenic compound. The level of disinfectant should be adjusted to the desirable level; this in turn will increase the cost of treatment. It is also expected that the product water quality is affected by the salt diffusion (mostly $\mathrm{NaCl}$ ) from the seawater to the draw solution side of the FO membrane. Salt concentration in the draw solution side is not affected by the MD process and it will remain in the product water stream. The concentration of salt in the product water will increase due to the draw solution recycling till it reaches the actual concentration level of salt diffusion across the FO membrane. The lower the membrane salt rejection rate the higher the salt diffusion. Practically, the salt diffusion in FO process using high salt rejection membrane (Rejection>99\%) was 2051 ppm; feed water concentration 34590 ppm (results as not shown here). The results in Figure $\mathbf{1 1}$ show the increase of salt concentration in the product water as a function of draw solution recycling. It is evident from Figure 11 that the concentration of $\mathrm{NaCl}$ in the product water increased with the number of draw solution recycling. After recycling 15 times the concentration of $\mathrm{NaCl}$ in the draw solution reached $2000 \mathrm{ppm}$. The concentration of $\mathrm{NaCl}$ in the product water reached the actual salt diffusion concentration, 2051.093 ppm, after recycle number 60 and remained unchanged.

The accumulation of $\mathrm{NaCl}$ in the product water renders it brackish. As a result it should be purged to reduce the salt concentration to the desirable level. Low pressures BWRO membrane can be employed to adjust the concentration of product water TDS.

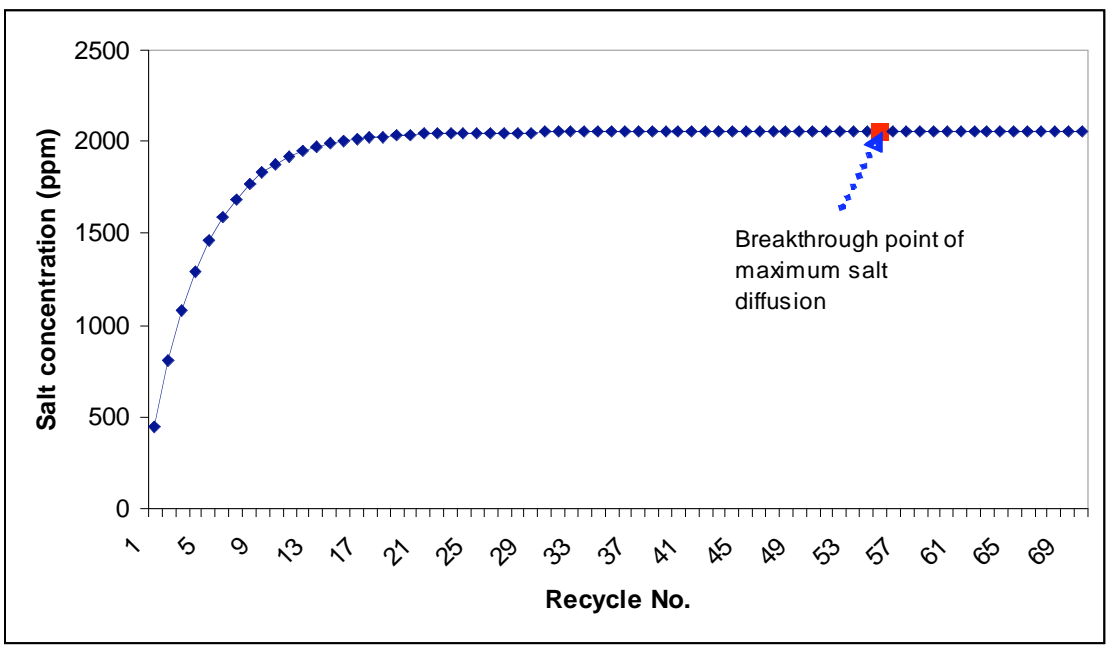

Figure 11: Concentration of $\mathrm{NaCl}$ salt in product water as function of draw solution recycle. 
Consequently, the total cost of the seawater treatment will be higher. There are a number of parameters affecting salt diffusion across the FO membrane such as feed concentration, type of the membrane, feed and draw solutions flow rate and temperature which need a further investigation.

\subsection{Thermal Processes for Draw Solution Regene- ration}

Thermal processes such as MSF and MED were proposed for the regeneration of draw solution and recycling [20]. MSF is very popular in the Gulf region of the Middle East due to the high salinity of the Gulf water. At the beginning of the $21^{\text {st }}$ century the new generation of MED was introduced and proven to be very competitive to the traditional MSF design [4, 22, 23]. MSF can be operated either by once through or brine recycle modes. The recovery rate in the once through mode is $10 \%$ while in the brine recycle is $33 \%$ [24]. Most of the current MSF plants are operated in the brine recycle mode to achieve a high recovery rate [4, 24]. In contrast, MED doesn't have the operation flexibility in MSF. A recovery rate of $33 \%$ can be reached in the MED plant. The high performance of MED and low energy requirements compared to MSF attracted a lot of attention especially when the fuel price is high. The top brine temperature in MSF is 110 ${ }^{\circ} \mathrm{C}$ while in MED is $65^{\circ} \mathrm{C}$ [25].

The cost of draw solution regeneration by thermal processes is expected to be higher than membrane filtration. In the latter case the feed water to the thermal processes is the diluted draw solution from the FO process. Thermal processes are more suitable for the regeneration of ammonia carbon dioxide than organic and inorganic salts such as sucrose, glucose, MgSO4, $\mathrm{MgCl}$, etc. because of the low temperature required for the evaporation of ammonia carbon dioxide. The following point should be observed upon using thermal processes for the regeneration of draw solution:

1. The potential of scale problems caused by the draw solution such as MgSO4 treatment by MSF

2. The diluted draw solution needs to be recycled more than often to achieve the desirable water recovery and draw solution concentration. As such the cost of regeneration will increase

As mentioned before, the expected concentration of ammonia dioxide in the draw solution is about $10 \%$ for seawater desalination, TDS 35000 ppm. In case of
MSF process, once thorough operating mode could be adequate for ammonia carbon dioxide regeneration (concentration $10 \%$ in draw solution). However, for other draw solution a recovery rate over than the conventional $30 \%$ is required to achieve the target osmotic agent concentration in the draw solution. Keeping in mind that if thermal processes are used in conjunction with FO for ammonia carbon dioxide regeneration, there will be salt residues in the fresh water as explained above in the FO-MD process. Therefore, an additional membrane/chemical treatment is required for the removal of salt from the product water.

\section{FORWARD OSMOSIS FOR POWER GENERATION}

Power generation from renewable sources such as solar, wind, geothermal has received a lot of attention due to the continuous increase in the fossil fuel prices and environmental awareness about green house gases emission. The idea of using $F O$ in power generation was dated back to the 70's of last century [26]. Sidney Loeb was first who suggested using osmotic energy in what so called Pressure Retarded Osmosis (PRO) in power generation [26, 27]. There are analogy between the application of $\mathrm{FO}$ in seawater desalination and power generation. In the latter process, two solutions of different concentrations are fed into the FO membrane. The high concentration solution is known as the draw solution while the low concentration solution is the donor solution. Fresh water transports across the membrane barrier from the low to the high concentration solution due to the osmotic pressure gradient. After leaving the FO membrane, the diluted draw solution is fed into turbine for power generation (Figure 12).

PRO can be used alone or in combination with RO process for power generation and seawater desalination [27]. As such, seawater is applied into the RO membranes for desalination. Permeate from the $\mathrm{RO}$ system is the product water while the concentrate is the donor solution in the FO process. This process has the advantage of reducing the brine concentrate discharged to sea. Although PRO was suggested long time ago, its commercial application wasn't achieved till 2009 when StatKraft company, Norway, built the world first power plant operates by the osmotic energy (Figure 12). The process was slightly different from that suggested by Sidney Loeb by in which an Energy Recovery Instrument (ERI) was incorporating to enhance the overall performance of the process according to the following equation: 


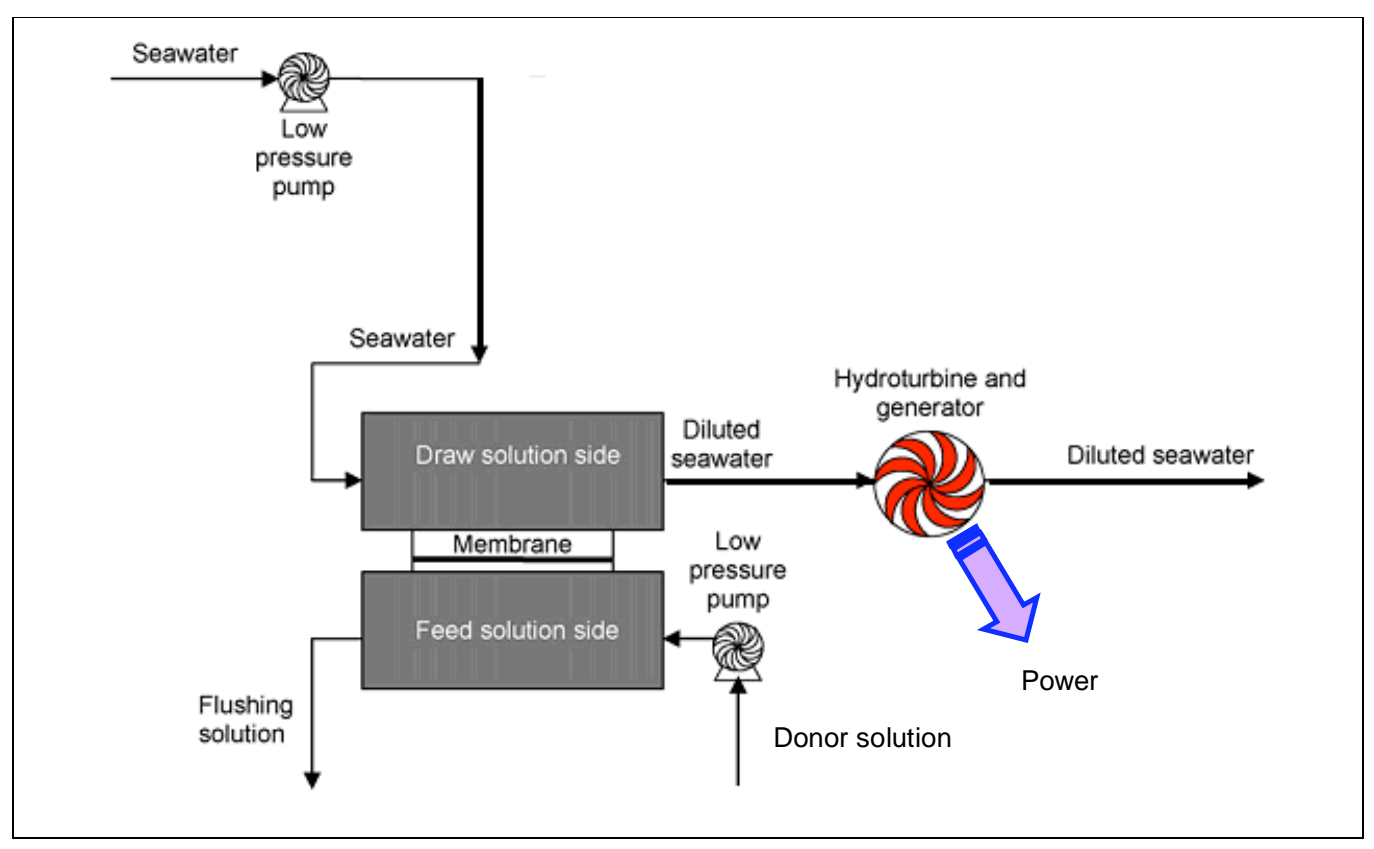

Figure 12: Schematic diagram of PRO process.

$$
E s=\frac{P V}{\mu}[2]
$$

Where $E s$ is the power generation from the PRO, $P$ is the pressure of feed solution to the turbine, $V$ is the volume of feed solution to the turbine, and $\mu$ is the pump efficiency. The generated power from PRO process increases with increasing the volume and pressure of the feed solution to the turbine system. Earlier FO membrane exhibited a low flow due to the adverse impact of concentration polarization (Figure 1). External and/or internal salt accumulation at the feed side of the membrane surface reduces the osmotic pressure gradient and hence the driving force for fresh water extraction. Luckily, new FO membranes dealt with this problem through reducing the thickness of the support layer which resulted in reducing salt accumulation at the membrane surface (Figure 14) [16]. This development encouraged scientists and pushed the PRO process a step ahead towards commer-cialization. The concerted efforts were culminated by building the world first power generation plant by using the PRO process [14]. Fresh water was used as feed solution while seawater was the draw solution. Using fresh water as a feed solution will eliminate the effect of concentrative concentration polarization at the membrane surface. However, the process is site specific; i.e. it is dependent on the availability of draw and feed solutions. In many countries affected by water shortage it is rather impossible using fresh water as a feed solution for power generation by the PRO process. Since water shortage problem has affected many areas around the world, seawater was proposed to be the feed solution provided that the draw solution must be a solution of higher concentration. In the latter design, the concentrative concentration polarization plays an important role in determining the net water flux across the membrane [15]. Indeed, PRO process for power generation using fresh water as a feed solution and seawater as a draw solution is a site specific process and can't be generalized worldwide. It depends on the abundancy of the feed and draw solutions in a particular area.

Alternatively, wastewater effluent was proposed to replace the fresh water as a feed solution in the PRO process to overcome the fresh water shortage problem $[10,12]$. Any impaired solution with low salinity can be used as a feed solution. The PRO process diagram using wastewater effluent and seawater as feed and draw solution respectively is shown in Figure $\mathbf{1 4}$. Wastewater effluent contains a number of impurities such as organic matters, total nitrogen (T-N), total phosphorus (T-P) and suspended solids (TSS). Organic matters presence, in particular, in feed wastewater effluent increases the propensity of membrane fouling propensity and affecting the overall water transport across the membrane [15, 28]. The coupled effect of organic matter and the concentration 


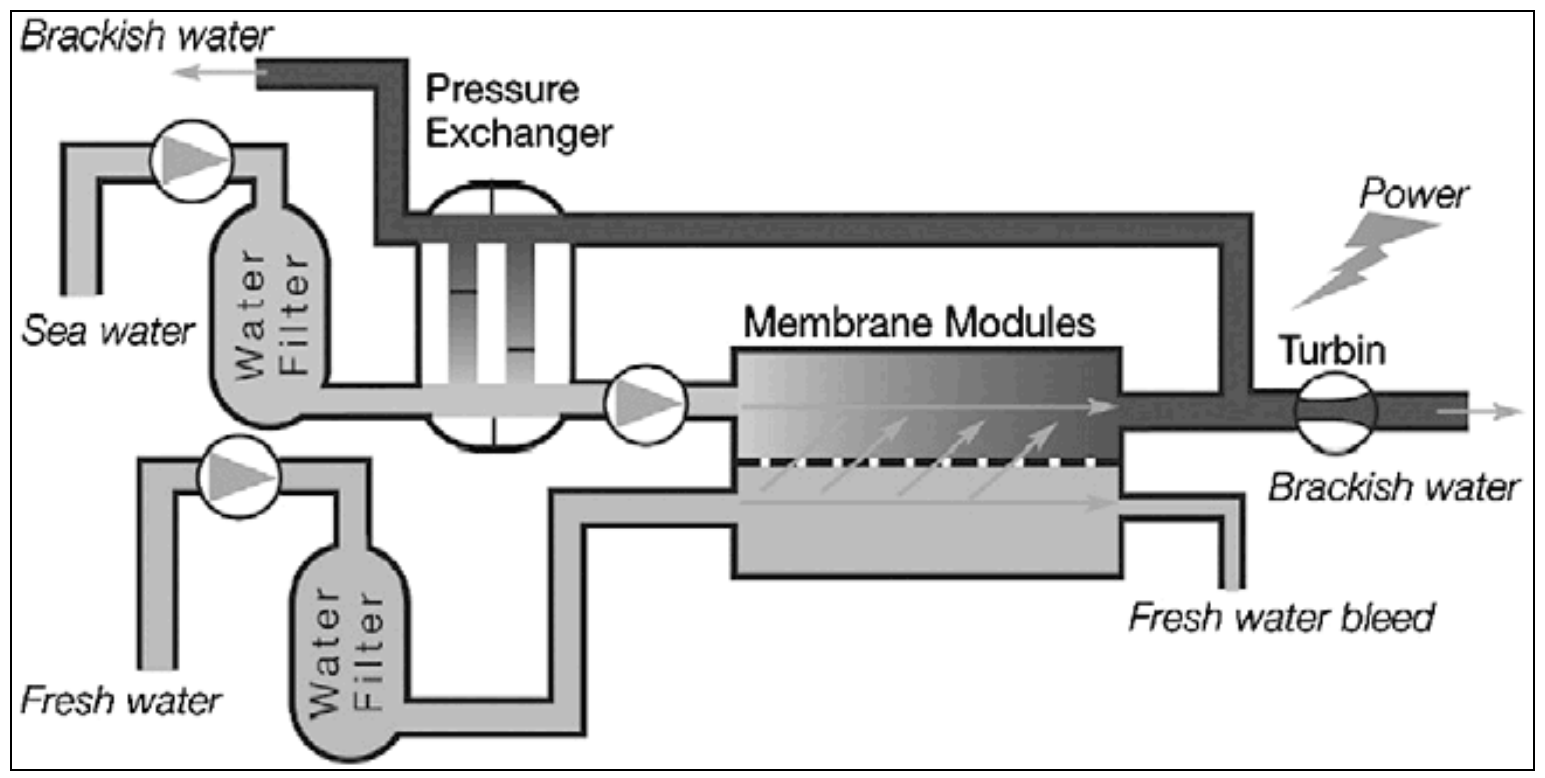

Figure 13: StatKraft PRO power generation plant (from StatKraft website).

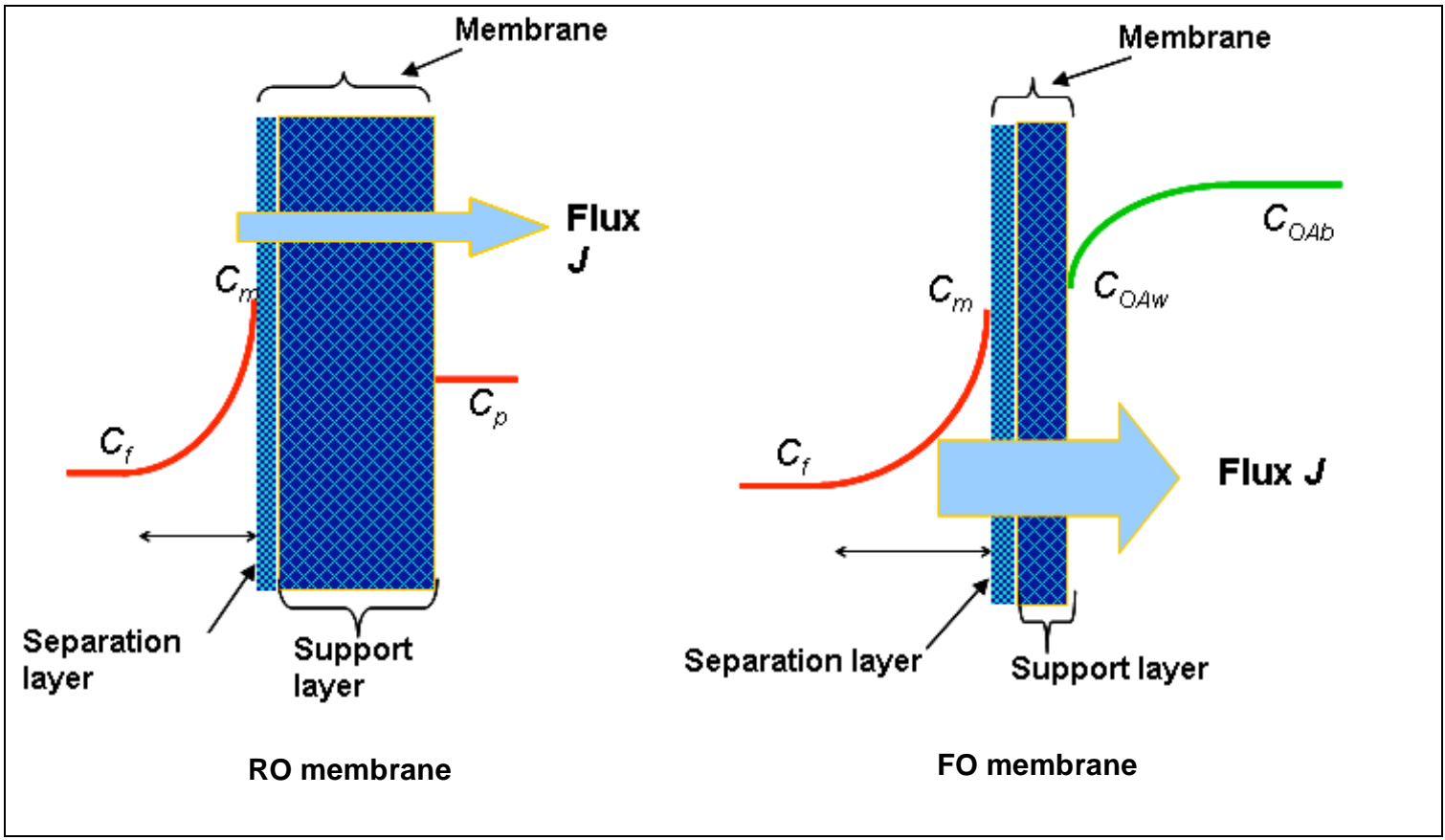

Figure 14: Concentration polarization in RO and FO membranes.

polarization effect were well investigated in the literature [15]. The experimental work showed that PRO operates better when the wastewater effluent facing the membrane surface while the draw solution facing the support layer [15]. Although such design reduces the osmotic driving force across the membrane but it is more efficient in reducing the coupled effect of organic matter fouling and concentration polarization.
Shung et al. suggested a conceptual PRO design using wastewater effluent as a feed solution while seawater was the draw solution (Figure 15). Part of the diluted draw solution is passed through a pressure exchanger for energy reuse then it is mixed with the rest of the diluted draw solution and sent to a second FO membrane. In the latter membrane a custom design draw solution is used for water extraction from the diluted seawater. Although using wastewater effluent as a feed solution will overcome the problem of 
fresh water shortage, the process performance will be lower than the fresh water feed. Organic matter fouling is the main drawbacks of using wastewater effluent as a feed in PRO. To alleviate the effect of organic fouling, wastewater effluent should face the selective layer of FO membrane while the draw solution faces the support layer. This operating mode is renown of yielding a lower membrane flux but more effective in reducing the FO membrane fouling [15]. Practically, the concentration of organic impurities in wastewater effluent varies depending on the type and level of wastewater treatment.

The PRO design shown in Figure $\mathbf{1 5}$ has two of FO membrane systems which makes it rather complicated. The diluted seawater from the first FO process can be treated directly by thermal or membrane processes for fresh water extraction and draw solution recycling (Figure 16). This will reduce the FO membrane area and cost. Additionally, the plant foot plant will be less.

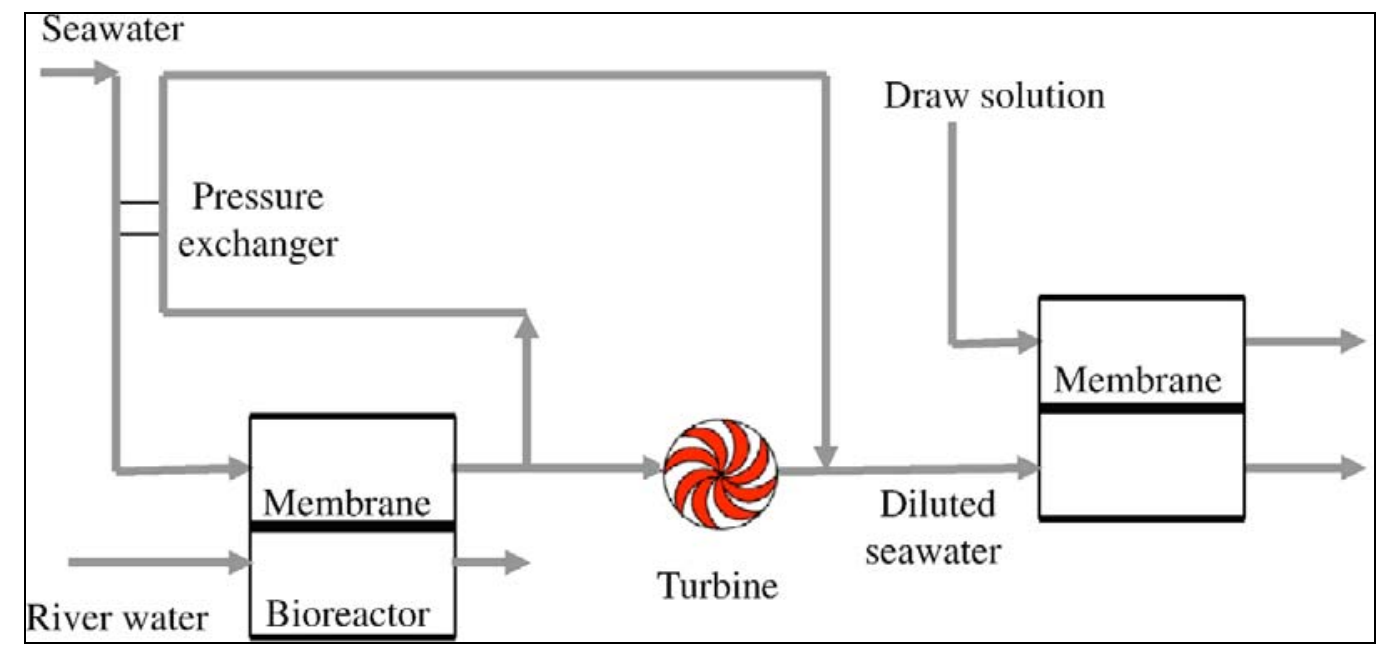

Figure 15: An integrated osmotic MBR, osmotic power generation and seawater desalination system (Tai-Shung Chung et al., 2010).

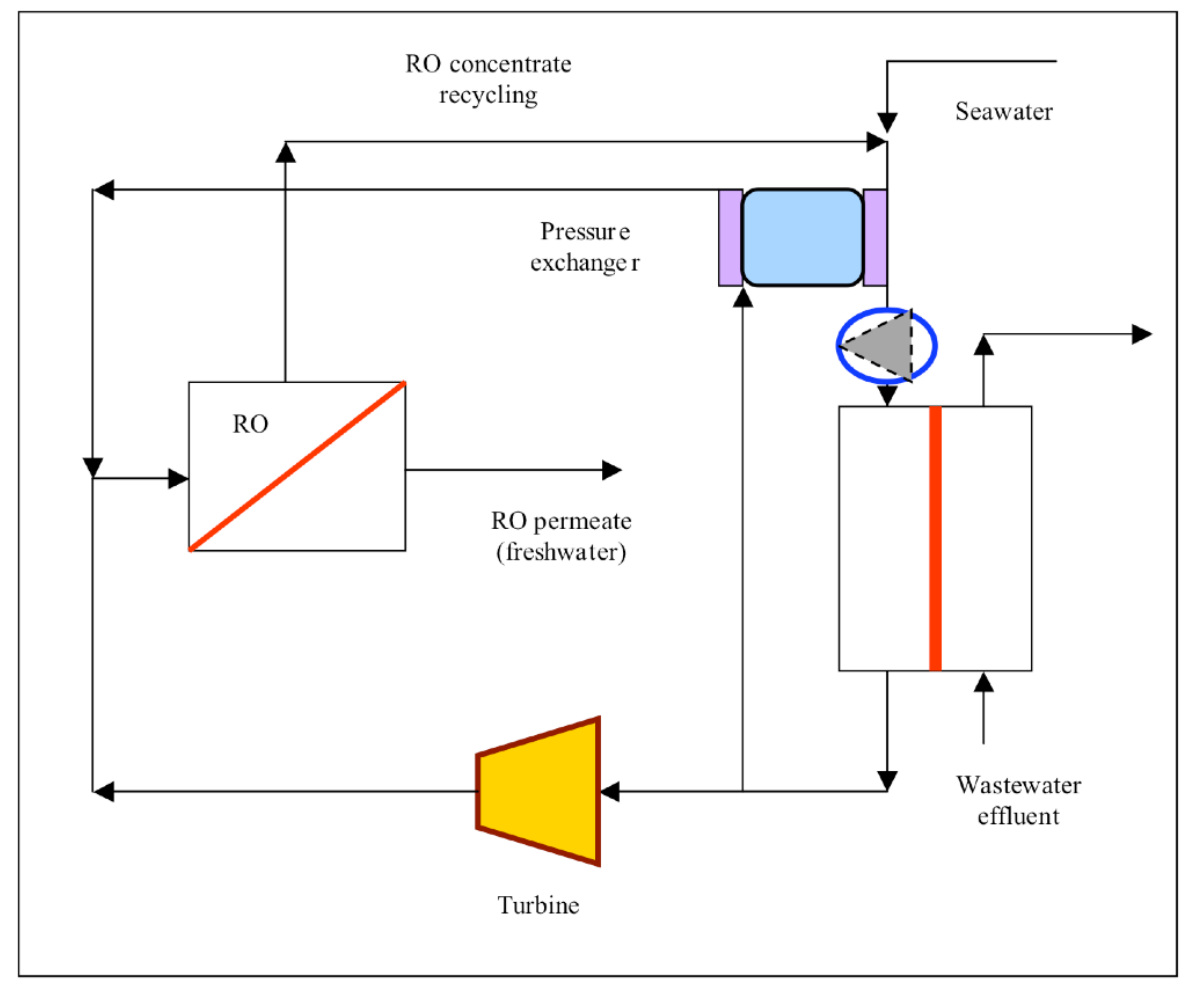

Figure 16: PRO process using wastewater effluent as a feed and seawater as the draw solution. 
The wastewater concentrate leaving the FO membrane can be used for irrigation or discharge to a proper water system. Either design in Figure $\mathbf{1 5}$ or 16 are an alternative to the use of freshwater and they need to be confirmed experimentally.

\section{Conclusion}

Despite the wealth of literature and experimental work conducted in FO membrane process, its application is still limited to bench and some pilot plant studies. In seawater desalination, the process is still under investigation. Its wide application in seawater desalination was hampered, at the beginning, due to the lack of appropriate membrane. Understanding the phenomenon of concentration polarization in the FO process has resulted in the development of a suitable FO membrane for seawater desalination. The real challenge encountered the commercial application of FO process was the economic feasibility of the FO and if it can be competitive to the existing membrane desalination technologies such as RO. Any successful application of $\mathrm{FO}$ requires a cost-effective regeneration process. This is because most of the energy required in FO desalination is spent in the regeneration process. Results from previous research studies suggested using NF membrane in the regeneration of tailored design draw solution constituted of large divalent ions such as MgSO4. Such design is more suitable for brackish water desalination as most of the available NF membrane can't tolerate feed pressure more than 40 bar. Different organic and inorganic salts were suggested to be used as draw solution. The simulation results in this study showed that $\mathrm{NaCl}$ is more efficient than $\mathrm{MgSO}_{4}$ and $\mathrm{MgCl}_{2}$ due to the higher recovery rate that can be achieved at lower power consumption. Osmotic agent of small molecular weight, probably, is more efficient draw solution than large molecular weight osmotic agent due to the higher osmotic pressure possessed by the former osmotic agent.

One of the inherent problems in FO is the salt diffusion from seawater to the draw solution side of the membrane. In particular, this is important when $\mathrm{MD} /$ thermal processes are used for draw solution evaporation and concentration such as in ammonia carbon dioxide. Low pressure BWRO membrane process can be used for salt removal from permeate to the desirable level. But the cost of the process be higher than the basic conventional design.

Additionally, FO process has the potential of application in power generation by what so called PRO process. The only commercial application of such process in power generation is the pilot plant built by StatKraft in Norway. Such process is a site specific as it uses fresh water and seawater as feed and draw solution respectively. Wastewater effluent was proposed as a feed solution and hence the geographic application of PRO is extended to include water shortage areas. However, membrane fouling by the organic matters in the wastewater effluent should be further investigated to reduce the treatment cost.

\section{REFERENCES}

[1] Mohammad Al-Sahali, Hisham Ettouney. Developments in thermal desalination processes: Design, energy, and costing aspects, Desalination 2007; 214: 227-240. http://dx.doi.org/10.1016/j.desal.2006.08.020

[2] Ioannis C. Karagiannis, Petros G. Soldatos, Water desalination cost literature: review and assessment, Desalination 2008; 223: 448-456. http://dx.doi.org/10.1016/j.desal.2007.02.071

[3] Kah Peng Lee, Tom C. Arnot, Davide Mattia, A review of reverse osmosis membrane materials for desalinationDevelopment to date and future potential, Journal of Membrane Science 2011; 370: 1-22. http://dx.doi.org/10.1016/j.memsci.2010.12.036

[4] Toufic Mezher, Hassan Fath, Zeina Abbas, Arslan Khaled, Techno-economic assessment and environmental impacts of desalination technologies, Desalination 2011; 266: 263-273. http://dx.doi.org/10.1016/j.desal.2010.08.035

[5] Lauren F. Greenlee, Desmond F. Lawler, Benny D. Freeman, Benoit Marrot, Philippe Moulin, Reverse osmosis desalination: Water sources, technology, and today's challenges, Water Research 2009; 43: 2317-2348. http://dx.doi.org/10.1016/i.watres.2009.03.010

[6] Robert L. McGinnis, Menachem Elimelech, Energy requirements of ammonia-carbon dioxide forward osmosis desalination, Desalination 2007; 207: 370-382. http://dx.doi.org/10.1016/j.desal.2006.08.012

[7] Jeffrey R. McCutcheon, Robert L. McGinnis, Menachem Elimelech, Desalination by ammonia-carbon dioxide forward osmosis: Influence of draw and feed solution concentrations on process performance, Journal of Membrane Science 2006; 278: 114-123.

http://dx.doi.org/10.1016/j.memsci.2005.10.048

[8] Kah Peng Lee, Tom C. Arnot, Davide Mattia, A review of reverse osmosis membrane materials for desalinationDevelopment to date and future potential, Journal of Membrane Science 2011; 370: 1-22. http://dx.doi.org/10.1016/j.memsci.2010.12.036

[9] Tzahi Y. Cath, Amy E. Childress, Menachem Elimelech, Forward osmosis: Principles, applications, and recent developments, Journal of Membrane Science 2006; 281: 7087. http://dx.doi.org/10.1016/j.memsci.2006.05.048

[10] Tai-Shung Chung, Sui Zhang, Kai Yu Wang, Jincai Su, Ming Ming Ling, Forward osmosis processes: Yesterday, today and tomorrow, Desalination 2012; 287: 78-81. http://dx.doi.org/10.1016/j.desal.2010.12.019

[11] Jeffrey R. McCutcheon, Menachem Elimelech, Influence of concentrative and dilutive internal concentration polarization on flux behavior in forward osmosis, Journal of Membrane Science 2006; 284: 237-247. http://dx.doi.org/10.1016/j.memsci.2006.07.049

[12] Andrea Achilli, Tzahi Y. Cath, Amy E. Childress, Power generation with pressure retarded osmosis: An experimental 
and theoretical investigation, Journal of Membrane Science2009;343: 42-52.

http://dx.doi.org/10.1016/..memsci.2009.07.006

[13] Sidney Loeb, Energy production at the Dead Sea by pressure-retarded osmosis: challenge or chimera?, Desalination 1998; 120: 247-262.

http://dx.doi.org/10.1016/S0011-9164(98)00222-7

[14] World Desalination Report, Vol 45, Issue 39, 26 October 2009.

[15] Chuyang Y. Tang, Qianhong She, Winson C.L. Lay, Rong Wang, Anthony G. Fane, Coupled effects of internal concentration polarization and fouling on flux behavior of forward osmosis membranes during humic acid filtration, Journal of Membrane Science2010; 354: 123-133. http://dx.doi.org/10.1016/j.memsci.2010.02.059

[16] Sidney Loeb, Leonid Titelman, Emmanuel Korngold, Joseph Freiman, Effect of porous support fabric on osmosis through a Loeb-Sourirajan type asymmetric membrane, Journal of Membrane Science 1997: 129: 243-249. http://dx.doi.org/10.1016/S0376-7388(96)00354-7

[17] M. A. Darwish, Hisham El-Dessouky, The heat recovery thermal vapour-compression desalting system: A comparison with other thermal desalination processes, Applied Thermal Engineering 1996; 16: 523-537. http://dx.doi.org/10.1016/1359-4311(95)00034-8

[18] Ian Lomax, Experiences of Dow in the field of seawater reverse osmosis, Desalination 2008; 224: 111-118. http://dx.doi.org/10.1016/i.desal.2007.02.085

[19] Mark Wilf, Kenneth Klinko, Optimization of seawater RO systems design, Desalination 2001; 138: 299-306. http://dx.doi.org/10.1016/S0011-9164(01)00278-8

[20] Abdulsalam Al-Mayahi (Worcestor Park, GB); Adel Sharif (Guildford GB, GB). Solvent Removal Process. United States patent US 20110114558. 2011 May.

[21] Mohamed Khayet, Membranes and theoretical modeling of membrane distillation: A review, Advances in Colloid and Interface Science $2011 ; 164: 56-88$.

http://dx.doi.org/10.1016/j.cis.2010.09.005
[22] Narmine H. Aly, Adel K. El-Figi, Thermal performance of seawater desalination systems, Desalination 2003; 158: 127142. http://dx.doi.org/10.1016/S0011-9164(03)00443-0

[23] Jacques Andrianne, Félix Alardin, Thermal and membrane processe economics: Optimized selection for seawater desalination' Desalination 2003; 153: 305-311. http://dx.doi.org/10.1016/S0011-9164(02)01128-1

[24] Ahmed M. Helal, Once-through and brine recirculation MSF designs - a comparative study, Desalination 2005; 171: 3360.

http://dx.doi.org/10.1016/j.desa1.2004.02.104

[25] Suresh Patel, Michael A. Finan, New antifoulants for deposit control in MSF and MED plants, Desalination 1999; 124: 6374. http://dx.doi.org/10.1016/S0011-9164(99)00089-2

[26] Loeb S., Norman R. S. (1975). "Osmotic Power Plants". Science 2003; 189: 654-655. . http://dx.doi.org/10.1126/science.189.4203.654

[27] Loeb S, "Energy Production at the Dead Sea by PressureRetarded Osmosis: Challenge or Chimera?", Desalination 1998; 120: 247-262.

http://dx.doi.org/10.1016/S0011-9164(98)00222-7

[28] Sangyoup Lee, Menachem Elimelech, Salt cleaning of organic-fouled reverse osmosis membranes, Water Research 2007; 415: 1134-1142. http://dx.doi.org/10.1016/i.watres.2006.11.043

[29] Bernard Vigneault, Peter G. C. Campbell, André Tessier and Richard De Vitre, Geochemical changes in sulfidic mine tailings stored under a shallow water cover, Water Research 2001; 35: 1066-1076. http://dx.doi.org/10.1016/S0043-1354(00)00331-6

[30] Mustafa, Syed, Shah, Khizar, Naeem, Abdul, Waseem, Muhammad, Ahmad, Tauqeer, Khan, Sadullah, Water, Air, and Soil Pollution 2011; 217: 57-69. 